\title{
Teaching Reform Based on Signal Detection and evaluation of curriculum
}

\author{
Bin GUO, Feng WANG \& Xuemei BAI \\ Electrical and Electronic Experimental Teaching Center, Changchun University of Science and Technology, \\ Changchun, China
}

\begin{abstract}
The teaching reform of signal detection and estimation curriculum for the graduate students is implemented which is based on the improved case method. The paper details the implementation steps about the reform and the change of the classroom atmosphere about graduate students. This method changes the teachers' teaching way. Its goal is to come up with the case by students and combines the teachers' guidance with students' reports and discussions. It can not only arouse students' enthusiasm tremendously, but also train students' abilities for thinking and innovating, which provides an efficient approach for training studyoriented personnel.
\end{abstract}

KEYWORD: Study-oriented; Case method; Signal Detection and Estimation

\section{INTRODUCTION}

Finding out questions and coming up with the reasons are the most important learning abilities in today's society, however, the overwhelming majority of the students have not mastered under the influence of higher education. Only after cultivating students' learning ability, can we make them have further broader thinking and finding more ways to figure out problems [1]. Obviously, with the rapid development of science and technology, the more innovative talents about science and technology a country has, the greater chance it would own in this competitive world. The innovation based on case method could improve the teaching impact, and it can make sure the students' knowledge, ability and quality meet the requirements of the society [2].

The course of signal detection and estimation is one of the specialized basic courses for the graduated students majoring in electronics and communication engineering and it is also an important academic degree curriculum[3]. However, there is a widespread phenomenon that graduate students pay less attention to this course and the classroom atmosphere is extraordinary depressed. Main reasons are shown as follows.

(1) The outdated teaching method

The traditional teaching method is a teacher's performance about the explaining of definition every time and then some examples will be given forward. For a deficiency of daily life instances, the process expounding theorems we need gets craggy and tedious. So it seems more and more difficult to be understood. Therefore, the phenomenon arises that there's no point in learning of theoretical knowledge and the only thing students want to learn is how to use the instruments they are required, which makes students neglect thinking and enthusiasm. The falling levels of education is deemed to it.

(2) The abstract teaching contents

The knowledge of signal detection gets too abstract to be understood so that many students want to ignore it. Invisible signal is liable to make obstacles for students to understand the knowledge. Nonobjective contents will cause tired mood, and the education efficiency will be reduced automatically.

(3) The simplex teaching method

The traditional teaching method still occupies the mainstream. The teacher is a speaker about the principles in front of the blackboard while all the students need to do is just listening. This way with the absence of interaction cannot form a good exchange between students and teachers. The information blocking means that you will be weeded out sooner or later ascribed to feathered information exchange nowadays. An experimental result made by a researcher team at Harvard University also revealed that people's attention span is about 20 minutes. In a 90-minute lesson how to grasp the students' attention will be the key to enhance teaching quality. 


\section{MEANING OF CASE METHOD}

Case teaching method is made up of many teaching cases. Teachers play a role of designers and prompters in this method. They encourage students to actively participate in discussion instead of the traditional way about teaching that a teacher is a knowledgeable scholar and what he/she just need to do is speaking. In other words, information is instilled in your head no matter if you can authentically comprehend it. The case teaching method originated in the 1920s was promoted by Harvard Business School in the United States, and it adopted the business management of the real situation or events as cases. Through this way, it can help to cultivate and develop the students actively participating in class discussions. Case teaching method is very suitable for the progress of advanced intellectual skills such as analysis[4], comprehensive, and evaluation ability.

But when this kind of method is applied to the teaching of postgraduates, its limitation is magnified immortally. As we all know, the postgraduates' courses aren't as basic as the courses of undergraduates. It makes it impossible to give all the time to students due to the level of the courses. And how to judge the effect of a class totally depends on the completion of the students' case which is assigned by their teacher.

In this case teaching, teachers will provide a number of cases based on the teaching content. Then, students are divided into a number of research groups for organizational literature review, research and discussion under the guidance of teachers. So this is a new teaching case which have been supplemented and improved. It not only needs the students' activity, referring to information, but also demands the teacher's changes of teaching content and way. It can improve students' ability to analyze problems, solve problems, so that the quality of students is enhanced. This approach achieves a pathway for the students to reading, thinking, analysis and discussion, and then naturally they will set up a suitable, complete and rigorous logic thinking method for their own. By changing teaching methods, our primary purpose is to stimulate students' curiosity, and enhance their interests in learning [5].

\section{IMPLEMENTATON OF CASE METHOD}

\subsection{Coming up with a question}

This course is divided into 12 independent chapters, so all the students in the class can be divided into groups with 5 members. Before the beginning of every lesson, the teacher will assign tasks to students. Certainly, these tasks must be consistent with the requirements of teaching syllabus and teaching aim. Let those students of this group find the origin of this knowledge, or the derivation process of a theorem. If it can be related to the story of a scientist, shows that he finishes the work perfectly. These items can minutely introduce how the principles were found, when the process was found and why it was found in this section. This is a kind of process teaching us how to learn, think and research. Two key points should be paid attention to when the teachers allocate tasks. One is that the themes should catch the students' eyes as soon as possible and the other is that class time should not be occupied by the lengthy and jumbled content.

\subsection{Gathering information in groups}

Students in the study group cooperate to finish the task. They should find the related chapters of the subject in the textbooks, and consult the correlative information through various ways. Network and library are good ways to find literatures and books about the courses. The advantage of it is to cut down the burden for graduated students, they can help each other if the projects are arduous and difficult. Everyone is responsible for the different information. Each case's background, theory and methods are different so that members of a team should communicate and discuss mutually. In the end, students should translate the information into a PowerPoint file for all the students in our class.

\subsection{Giving a Report}

The study group, with a finished PowerPoint file, chooses a representative before the lesson. He or she will show the research result of their group on the platform. Students will gradually understand the main content in this lesson and their mind will form a viewpoint of "this is what the principle is", because the main content of this topic is related to the background knowledge, or practical application. If someone's show is a knowledge discovery process, it can lead the students to understand the process of a scientific research. The time of a speech should be limited to 15 minutes, because of the limitation of class time.

\subsection{Replenishing by teachers}

The teacher begins to formal lectures after the student's speech. This is a very important link of the method. On the last step, students may talk about content of this lesson, or someone might expound the application of the concrete practice about the knowledge points in the lesson. At this time, what teachers need to do is to guide the student to understand the content of this course detailed. What the teacher mainly expounds is why we need it and how we get it instead of what it is. We should not give priority to the formula proved with 
mathematical derivation. Tedious mathematical proof process should be simplified, and the solution is given in next steps.

\subsection{Exchanging information}

Comparing with a complex mathematical calculations, the discovery process of the principle can greatly arouse people's curiosity. If there are any students interested in what you say, communication of lecture notes is essential. They should build a communication tool for this class with BBS or communication group. Students or teachers can uploaded their notes to the BBS and anyone who is interested in it can download them. The tedious process of mathematics made no mention at class time can be uploaded to the site in the form of lecture notes. Students who really need it will take it. The greatest characteristic of the site lies in his interactions. Students can consult the problems that they do not understand in this site.

\section{CONCLUSION}

In conclusion, the new case teaching compared with traditional case teaching method realizes the interaction between teachers and students. Students can save a lot of time used to derived formula of the theorem. Therefore, they have more time to elaborate the theory of complicated knowledge. It can help students find their interest and the direction of research. It can make a change for students from accepting learning passivity to learning with a lot active thought. Then, students can effectively avoid that the engineering students we are cultivating become "skilled workers". It greatly arouses the enthusiasm of the students to learn while also exercise the thinking ability of students. This is the guarantee of cultivating highquality talents for China. Of course, there are many disadvantages in this method. If the student's enthusiasm is not high, the classroom atmosphere will be very awkward. So, many aspects still need to be improved.

\section{REFERENCES}

[1] J.J. Peng. (2010) Education reform and development of important opportunities, Education of Hunan Province.

[2] Y.Q. Yang. (1987) Changing education idea. Explore of Education.

[3] S.S. Li. (2010, December). The lighthouse of education reform. The New Education.

[4] J. Lu. (2008, April). The origin of education. Journal of East China Normal University.

[5] J.S. Ma. (2002) Theory of conflicts in the process of education reform. Education Science. 